\title{
KOKO-BERA ISLAND STYLE MUSIC
}

\author{
Paul Black and Grace Koch
}

While studying the Koko-Bera language in Kowanyama, Queensland during 1977.1978, one of the authors of this article, Paul Black, had the pleasure of becoming acquainted with the 'island dance' style that has become populat in many Aboriginal communities in Cape York Peninsula within the present century. It is interesting to see how the lyrics often encode social commentary or how they commemorate historical events. Traditional mainland Cape York Peninsula songs may also use such subject matter, but published accounts of traditional music have usually concentrated on songs used for ceremonial purposes.

This article grew out of a need to provide a brief and largely non-technical characterisation of island dance and its significance in an Aboriginal community, using Koko-Bera dances as concrete examples. A short technical description of the musical style is included at the end. Many island style songs have been recorded by ethnomusicologists, linguists, and others during the past two decades, but little about the style has been published although the unpublished work of Wolfgang Laade (19631964) and various works by Alice Moyle, Jeremy Beckett and Athol Chase do give useful information. Much musicological work remains to be done on the tape collection of Cape York Peninsula island style songs held at the Australian Institute of Aboriginal Studies, which is the largest such collection in the world.

Three of the five Koko-Bera songs to be described here were composed jointly by the late Ephraim Gilbert (1927-1978) and Isaac Zingle (born 1934). The song, 'Koko-Bera Ground' was composed by Mr Zingle, who is also notable for creating a Koko-Bera version of the popular song, 'Pearly Shells'. Working with the help of elders best able to advise on the wording of Koko-Bera lyrics and others in the community, both men have been prolific composers. ${ }^{1}$

Paul Black is presently lecturing at the Australian School of Linguistics. Formerly a Research Fellow at the Australian Institute of Aboriginal Studies, he has studied in detail the Kurtjar and Koko-Bera languages of Queensland.

Grace Koch is the Audiographer (Music) at the Australian Institute of Aboriginal Studies. Her main publications are in the field of sound archiving, and she has done field work on the music of Kaytej women in Central Australia.

1 We are grateful to these composers and to others in Kowanyama for all the help that they provided, and to $\mathrm{Mr}$ Zingle in particular for his assurance that we may use these songs here; in doing so we recognise that copyright remains in the hands of the composers or their heirs. We would also like to thank Dr Alice Moyle, Dr David Zorc, Dr Anna Shnukal and Dr John von Sturmer for helpful advice and criticism, and the Australian Institute of Aboriginal Studies for funding Black's research. 


\section{THE ORIGINS AND NATURE OF ISLAND DANCE}

Although the present paper restricts itself to island style music as practised on mainland Cape York Peninsula, a similar style is found throughout a large portion of Oceania. Black has seen dances from both Torres Strait and Papua New Guinea that he would be hard pressed to distinguish from Koko-Bera dances in their general style of singing and choreography. 'Sitting dances' of the type performed in Torres Strait will not be included in this discussion.

Originally island dance came from Pacific islanders whose musical style filtered down through Torres Strait to Cape York Peninsula. ${ }^{2}$ When the London Missionary Society arrived on the shores of the Torres Strait Islands in 1871, they brought with them as preachers eight recent converts to Christianity from the Loyalty Islands. A second wave of missionaries in the 1890s included teachers from Samoa and Niue. Both of these waves brought Pacific island hymn tunes and island dance. Since traditional Torres Strait dancing was frowned upon by these missionaries, Pacific island dance was taught as a substitute, thus becoming the popular music and entertainment of the day. ${ }^{3}$ Laade has also discussed the arrival and development of the general style in Torres Strait and documents the introduction of the style to Australian mainlanders at Lockhart River Mission on the east coast of Cape York Peninsula. ${ }^{4}$ He states that three Torres Strait islanders came to the mission at the time of its founding in the early 1920s and taught the style of dancing and singing that they had learned through contact with other South Pacific peoples. In the early 1960s, in fact, Laade met one of the Murray Islanders who first instructed the mainlanders of the area in island style in 1925. Chase posits that island dance was popular amongst European administrators and Church officials because of its colour and drama and its lack of a mythological base, therefore separating it from mainland culture. $^{5}$ The Anglican missions at Lockhart, Edward River, and Mitchell River facilitated the introduction of island dance by using islanders as religious teachers to the mainlanders.

Further contact came as Torres Strait men worked on pearling and trochus luggers with Lockhart men. Since the islanders were generally not allowed to go ashore and visit the mission in the early 1920 s, much of the music instruction occurred amongst the mixed lugger crews as they worked and when they camped at night on uninhabited islands. The instruction was not totally one-sided. While Laade was recording songs at Murray Island in 1963-65, he found several songs in mainland style in Aboriginal languages that the islanders had come to refer to as 'rob wed' or 'serenade song'. 6 'Rob wed' includes Torres Strait songs as well, and it would be interesting to know why the islanders put the Aboriginal songs into this category.

Conceivably island style could have come to the mainland even earlier. One Torres Strait Islander was involved with the founding of Mitchell River Mission (later

\footnotetext{
2 Moyle 1968-1969:13

3 Beckett 1978:212-219.

4 Laade 1963-1964, vol. 1:13.

5 Chase 1980:361.

6 Laade 1963-1965, vol. 3:11; Haddon 1898:158.
} 
Kowanyama) on the west coast of Cape York Peninsula in 1905, and crews from luggers were drawn from all parts of the Peninsula, although the seafaring Aborigines of the east coast were especially adept at the occupation. In any case, island style is found throughout most of the coastal areas of the Peninsula, especially in the communities that originated as mission stations. On the west coast, island style is found as far south as Kowanyama, but apparently not among the Aborigines raised on the cattle stations to the south and now concentrated in the town of Normanton. Island style has become popular in other parts of Australia as well, such as Roper River in the Northern Territory, but this paper will only concern itself with Cape York Peninsula.

\section{ISLAND DANCE AND 'OLD PAYTEN'SINGING}

There are several types of singing in Cape York Peninsula, some of which are as innovative as island dance. In this discussion we will limit ourselves to a comparison with the mainland style known as 'old payten'(suggested as a term for 'old fashioned'). 'Old payten' songs may be used in initiation rituals and many are restricted in use. On the other hand, island dance is not used in initiation rituals. Occasionally, though, words from restricted ceremonies may be included in island dance songs, albeit phonetically rearranged. Laade documents one such song from Lockhart River, composed by Johnny Short. ${ }^{8}$ This form is always composed by initiated men with approval from the relevant leaders. Island dance is most commonly performed at public ceremonies such as house openings, sports days and other public festivals. ${ }^{9}$ Whereas portions of initiation ceremonies are closed to women and children, island dance is a form of community activity that draws everyone together, providing for an arena of competition.

This rivalry occurs amongst squads of dancers who compete for audience approval. Chase identifies the teams at Lockhart River as being created from amongst identity groups at the level of 'tribes' as they are recognised within the coastal groups. ${ }^{10}$ Inlanders have no separate teams; instead they support the coastal 'tribe' with which they believe their groups were traditionally aligned. Each team is named from a mythological figure associated with initiation ceremonies, and each has its own practice area, song repertoire and dance stories. No team may sing a song owned by another, and ownership is held either by the living composer or is inherited patrilineally from remembered ancestors. The dancers in the front row are considered to be the 'stars' of the performance. Each front row dancer exhibits a personal style, often exaggerating the dance motions, in order to win the cheering approval of the audience. ${ }^{11}$ During a performance, wives are expected to sit with their husbands' identity groups, but they may sing with and offer support to their own groups as well.

\footnotetext{
7 John von Sturmer, personal communication.

8 Laade 1963-1964, vol. 1:53.

9 Chase 1980:225-226.

10 Chase 1980:226.

11 John von Sturmer, personal communication.
} 
In terms of composition of songs, there is a basic difference in 'old payten' and island dance. People 'receive' or 'find' 'old payten' songs, often in dreams. They are a gift from ancestors or totemic beings and are seen as being pre-existent. Island dance, however, is consciously 'thought up', and is seen to be totally a creative activity. When an island dance is composed, certain formal elements must be observed. Unlike mainland styles, island dances give great emphasis to the entrance and the exit phases of the dance. Often the dances are performed in groups of three. Even the rehearsal techniques of island dance differ from 'old payten'; the latter is always practised one at a time, whereas several island dances may be rehearsed simultaneously within earshot of one another. ${ }^{12}$

Finally, the use of props may differ in the two styles. Chase did not observe body paint, bush ornaments, or mainland weapons being used at Lockhart in island dance. ${ }^{13}$ Von Sturmer has seen shields used during island dance at Aurukun. The distinctive garb for island dance at Lockhart River includes long waistcloths and white bandages around wrists and ankles. White headbands and elaborate headdresses may be worn in other venues, and von Sturmer has seen props, such as small aeroplanes, tied to the bodies of dancers at Aurukun. Both men and women may dance and, unlike 'old payten' performances, dancers also may sing.

\section{SUBJECT MATTER OF SONGS}

The subject matter of the songs is typically drawn from the experiences of the composers, as is true for the songs to be described. This is not known to be the case with 'old payten' songs, although it may well be the case for 'play corroborees'. Lyrics of island style songs often narrate a strong emotional theme, such as absence from one's relatives or sweethearts or of the dangers of bad weather while working on lugger crews. ${ }^{14}$ In Aurukun, aeroplanes flying to the west are often mentioned, with 'west' being synonomous for 'death'. and the 'aeroplane' standing for 'change'.15 A 'shake-a-leg' song recorded by Bruce Sommer about the 'cattle station manager'16 is pointed social commentary, and in Normanton Black recorded mainland style songs about such matters as 'the mailcoach', 'the Chinaman', the first arrival of an aeroplane, and using paper to wrap up a dinner to be taken out to Two Mile Creek.

Although the subject matter can be similar, the language of island style and 'old payten' song words often differs considerably. 'Old payten' lyrics of the area tend to consist of brief phrases, repeated with considerable distortion for musical purposes. For example, the lyrics of the mainland style 'Dinner Paper' song involve only two distinct English phrases, 'dinner paper' and 'Two Mile Creek'. 'Old payten' songs also tend to contain archaisms - or at least, words whose meanings may be unknown even to the owner of the song - and sometimes even mixtures of different languages. One Kowanyama area song cycle contains a stanza that begins in a Koko-Bera dialect

\footnotetext{
12 John von Sturmer, personal communication.

13 Chase 1980:32.

14 Chase 1980:225.

15 John von Sturmer, personal communication.

16 Bruce Sommer, personal communication.
} 
and ends in Oykangand. The lyrics of island style songs, on the other hand, tend to consist of sentences very similar to contemporary spoken language, although with such differences as will be noted later. ${ }^{17}$

\section{MUSICAL CHARACTERISTICS}

Musically island style differs from mainland styles in several ways. 'Old payten' music has a single melodic line which may be sung polyphonically whereas island style is sung in harmony. The influence of Western church hymns upon South Pacific songs may help to account for this. However, island style music tends to use 2 or 3 part harmonisations rather than 4 part hymn style harmony, and island style songs almost always end on a unison note or an octave instead of a full tonic chord sounded at the end of hymns and church songs. A second difference from the mainland comes in the range of songs. Mainland tunes may not use more than two or three adjacent tones, whereas island style songs easily encompass an octave or more.

Vocal technique differs markedly in the two styles. A 'tense, tremulous vocal quality' is evident in the singing of Fanny Parrot from Kowanyama in the performance of traditional Koko-Mindjen songs. ${ }^{18}$ Women's 'wuungka' songs, used in mourning, display a constricted vocal tone. However, island style singing is characterised as having a more 'open throated manner' with a strong nasal quality which projects very far. ${ }^{19}$

The instruments used to accompany island style music are quite different from those used in mainland music. Most songs are accompanied by chords played on guitars (or ukuleles) and by drums. The latter may be a flour drum placed on its side and played with sticks on either ends or in the middle. The Koko-Bera also use a Torres Strait style drum - a concave wooden tube with a single goanna skin drum head. The above-mentioned flour drum tends to assume an hourglass shape as well, owing to the pressure applied by the sticks to the middle. Some groups other than the Koko-Bera use seed rattles, or segments of the matchbox bean strung together. ${ }^{20}$ Apparently those in use at Kowanyama were purchased from Torres Strait Islanders. Body percussion, often handclapping, and shrill whistle calls to the dancers also accompany island dance. Both the dancers and the seated instrumental section sing as well as the audience.

The choreography of island dance differs from other mainland styles, such as 'shake-a-leg', in that it usually involves a military-like formation of ten to twenty dancers moving more or less in unison. 'Shake-a-leg' is performed solo or as part of a small group with the dancers using an extreme spread leg movement, but island dancers keep the legs stepping forward more closely together. As mentioned earlier, island dancers do not use body painting. The Koko-Bera decorate themselves with coloured strips of palm leaf hanging from the upper arm, lower leg, and over their shorts or trousers. Occasional dances involve one or two women wearing such 'grass

17 See also Alpher (1976) for a comparison of the language of island style and mainland style music of the Yir Yoront of Kowanyama.

18 Moyle 1968-1969:10.

19 Moyle 1968-1969:6.

20 Moyle 1978:15. 
skirts' over their clothes as they dance something akin to the hula amongst the male dancers. At Aurukun, men may also do this 'hula', and great merriment results. Some groups may wear headdresses, but the Koko-Bera were not seen to do this. During a dance, women from the audience sometimes march between the rows of dancers and sprinkle talcum powder on the backs of one or more of the dancers, thus showing formal recognition of relationship and support. ${ }^{21}$

\section{THE SONGS AND THE DAVCES}

\section{1. 'Koko-Bera Ground' and the dance competition}

It seems appropriate to begin a discussion of the Koko-Bera dances with what is virtually an anthem, 'Koko-Bera Ground'. For this and the other dance songs we give the musical notation accompanied by the lyrics as sung, the lyrics as spoken accompanied by a word by word translation, and finally a relatively free translation into English. Some linguistic characteristics of the sung and spoken lyrics of the songs are pointed out in the following section; for the moment we will consider only the significance of the ly rics.

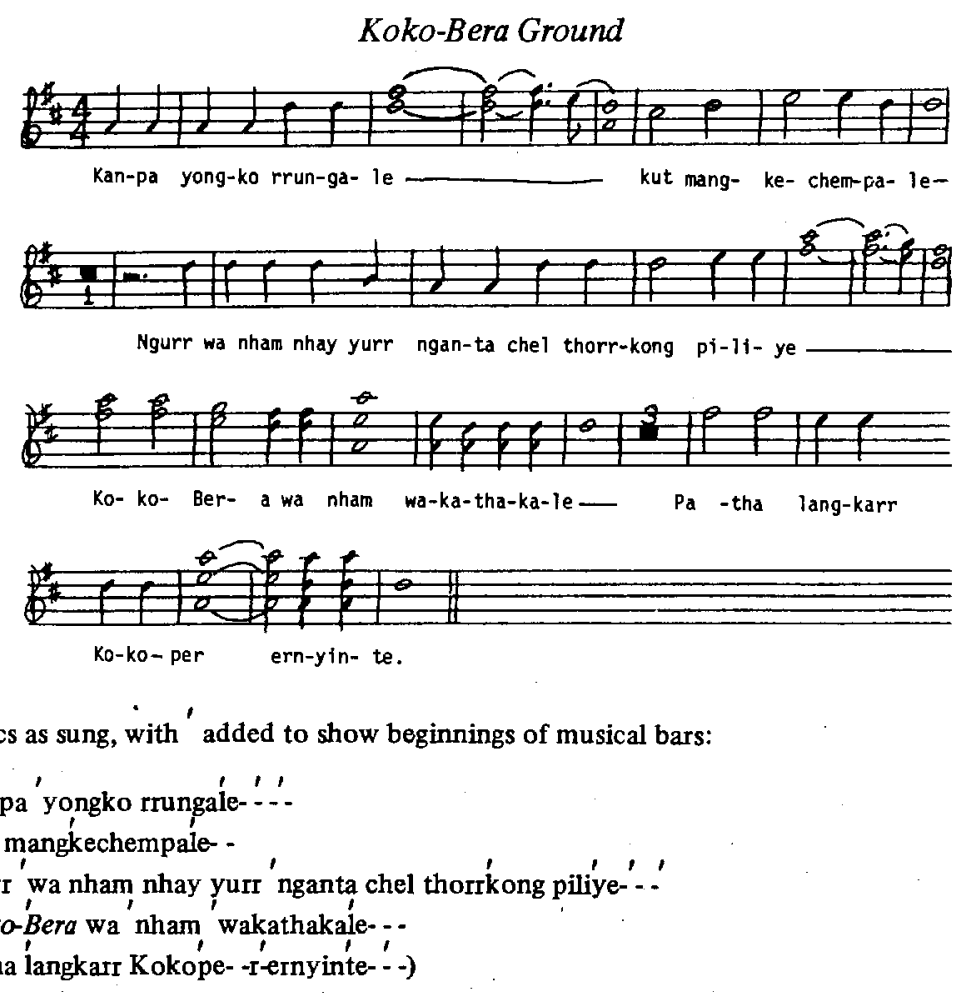

21 Chase 1980:226. 


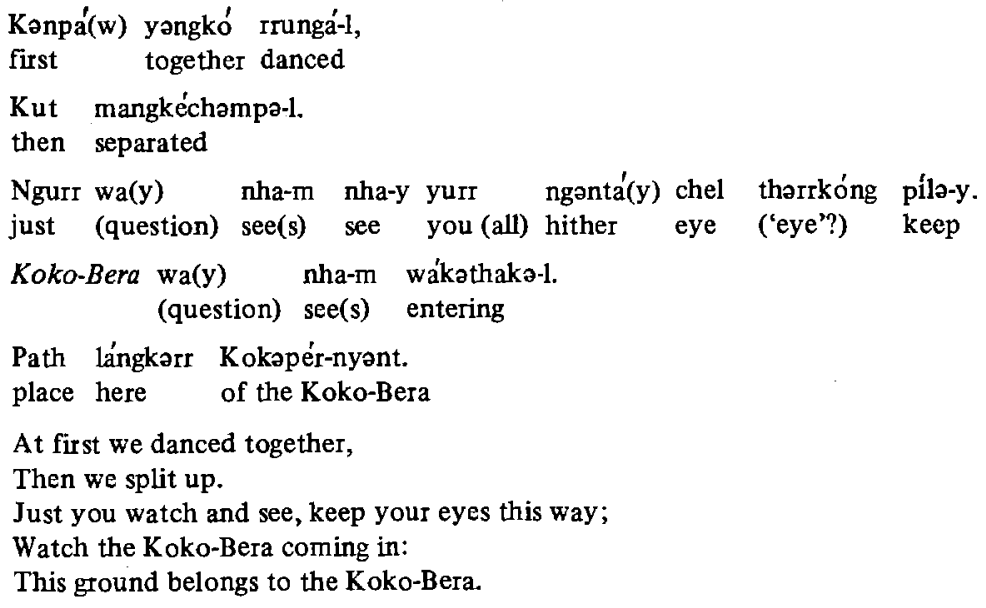

\section{The language of the lyrics}

Island dance lyrics tend to deviate from normal spoken Koko-Bera only in a few respects. The most obvious differences are in pronunciation, as can be seen by comparing the lyrics as they are sung with the spoken versions of these lyrics. In this regard, note that most of the Koko-Bera sounds have been written in a 'practical' orthography much like that used for the more widely spoken and written Wik-Munkan language, to the north. Rather than dwell on details of pronunciation here, we simply list the consonants and vowels in an order commonly used by linguists to characterise the articulations of speech sounds:

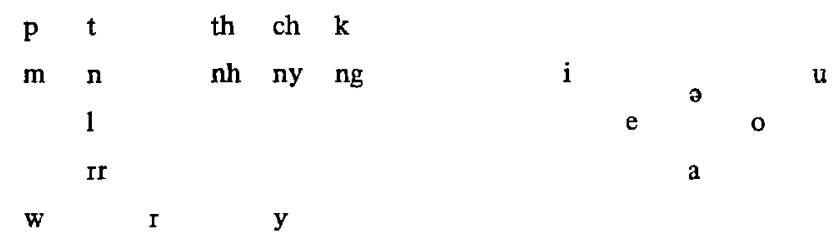

The most obvious phonological characteristic of island style singing is the addition of the vowel e to words to make it possible to prolong the end of a melodic line; only a few Koko-Bera words, such as yangkó (alternatively yangkórr) 'together' or 'with', end in vowels in speech. The normal position of primary stress, marked acute in this and other words, is maintained in singing only to the extent that it is often made to coincide with the musical beat. Another difference is that the schwa vowel e, which occurs only in unstressed syllables, in generally sung as one of the other vowels, $\mathrm{i}, \mathrm{e}, \mathrm{a}, \mathrm{o}$, or $\mathrm{u}$ unless its duration is less than a quarter note. To some extent schwa can also be pronounced much like one of these other vowels in speech: for example, the sequences $\partial y$ and $\partial w$ are commonly pronounced as $i y$ and $u w$ respectively in both speech and song. Sometimes it can not be - lángkarr 'here' is never pronounced as langkarr except in singing, for example - and in such cases the schwa is sung as the vowel a. (To linguists this could perhaps suggest that schwa is an unstressed equivalent of the vowel $\mathrm{a}$, but for morphophonemic reasons it seems somewhat better to take it to be an unstressed equivalent of e. It would rarely be confusing to write it as either a or e in a practical orthography.) 
The final consonants shown in parentheses are not pronounced when the lyrics are sung, but these are often elided in speech as well. Final $w$ and $y$ are almost never pronounced unless at least a brief pause follows; we have not bothered to enclose them in parentheses when their elision is not obvious, as in ay (usually pronounced $i y$ or simply $i$ ). Such consonants as $\mathrm{p}, \mathrm{k}$, and $1 \mathrm{can}$ be elided in speech when the next word begins with the same consonant, although alternatively the like consonants can be separated by a schwa-like vocoid. This elision can be seen in the name Kokaper 'Koko-Bera', which was originally a compound kok-kaperr 'speech-proper'. We continue to use the English spelling Koko-Bera here, even though the hyphen is clearly misplaced, because such spellings are familiar to the people of Kowanyama. The song 'Koko-Bera Ground' seems to contain both the English pronunciation of the name such English words are given in italics - and the Koko-Bera pronunciation, although one sung with the sequence $e r$ repeated at the beginning of the next bar of music.

The grammar of island dance lyrics deviates little from normal spoken Koko-Bera. In 'Koko-Bera Ground', for example, the subject 'we' of the first two lines is not given overtly; such ellipsis occurs in normal spoken Koko-Bera, but only when the subject is clear from preceding discourse or other context. Wa(y) nha-m nha-y, translated 'watch and see', seems ungrammatical in more traditional Koko-Bera, but possibly it is quite acceptable in the less fluent speech of the youngest (albeit middleaged) speakers of the language. Wa/y/nha-m is commonly used as if it were an imperative verb meaning 'watch', but it is literally a question meaning 'do (you) see?', and such a question is not normally conjoined with a true imperative, in this case $n h a-y$ 'see'. Possibly the lack of occasional suffixes where expected in the lyrics of other island dance songs is also typical of less traditional Koko-Bera and thus does not represent a real difference between song and speech. We will not deal further with the grammar here, but in giving the lyrics as spoken we have used hyphens to divide words into roots and suffixes, and the glosses accompanying the words should suggest the functions of the latter.

\section{2. 'Old Paintin' Dance' and social commentary}

When Black first heard the term 'old payten', he interpreted it to mean 'old paintin' and associated it with dances where the performers 'paint up'. Like 'Koko-Bera Ground', 'Old Paintin' Dance' is a comment on the contemporary social situation, in this case on the passing of certain traditions. Both the 'old paintin' (i.e. traditional) dance called Warrongamélngan and the Crippled old Man story belong to the Pekapenpew local group, to which the deceased composer belonged.

As the last line says, the people who used to know these traditions are now largely 'dead and gone' - here 'in the west', because this is the direction of Pekapenpew territory, just north of the mouth of Topsy Creek, from Kowanyama. That the Pekapenpew have lost some of their main traditions is not surprising in view of how quickly this group took advantage of some of the more beneficial aspects of white culture; the father of the deceased composer had in fact been as far away as Sydney for schooling very many years ago. These traditions, however, were not entirely lost at the time the song was composed. In 1978 the Warrangamelngan was still remembered by an alderly and blind widow of a Koko-Bera man - she herself was from a more northern group; she sang this song at the ceremony that removed the 


\section{KOKO-BERA MUSIC}

\section{Old Paintin' Dance}
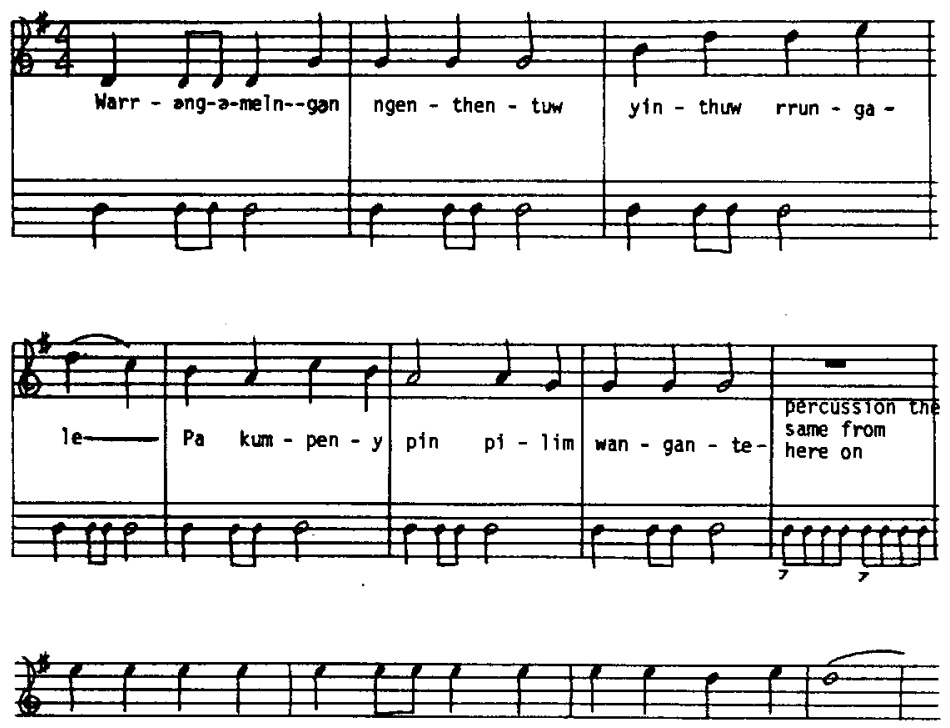

Pe - ka - pen - pew Warr - ang-a-meln - gan kan - pa rrun - ga - le -
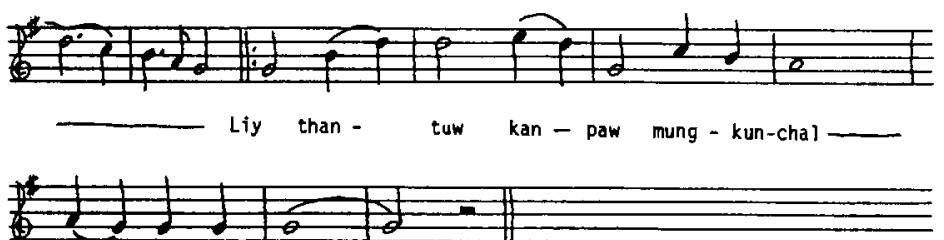

$11 y-$ wal - pi - ye

(lyrics as sung, with 'marking beginnings of musical bars:

'Warrangamelngan' ngenthentuw' yinthuw mungale- -

'Pa kumpeny 'pin pilim 'wangante-

'Pekapenpew 'Warrongamelngen ' kanpa rrungale- '..'

'Liy thantuw kanpaw mungkunchal 'liy walpiye- -)

Warrangemélngen nganthéntow yinthow rrungá-1, (dance name) we (exclusive) before danced

$\mathrm{Pa}$ kumpény pin pílə-m wángant.

human crippled ear listening from the west

Pekəpenpéw Warrongamélngen kənpá(w) rrunga-l. (group name) (dance name) first danced

Liy thántəw kənpáw mungkunchá-1 liy wálpəy.

yonder they first became extinct yonder west

We used to dance the Warrangamélngan,

Listening to Crippled Old Man from the west.

The Pekapenpéw danced the Warrangamélngan before;

Those early ones are dead and gone in the west. 
taboo on the house of the deceased composer some three months after his death in early 1978. It also proved! possible to record several hours' worth of the Crippled Old Man story from the eldest 'Yir Yoront man in Kowanyama.

Aboriginal traditions arre undergoing change and loss throughout Australia, but the forces behind this can vary considerably. The Koko-Bera people are luckier than most to the south because they have had relatively few changes forced upon them. It seems that the mission did actiively discourage some traditional activities - for example, they built a cattle slaughtrering pen on top of one of the initiation grounds. Yet they seem to have left many others undisturbed, and one of the first missionaries, the Reverend F. Chapman, O.B.E., who arrived in the 1910s, is said to have become fluent in at least Koko-Bera. The Koko-Bera themselves have actively embraced such cultural innovations as island dance, and they have found it useful to incorporate aspects of European culture into suclh traditional ceremonies as those concerned with death and mourning, in which the unveiling of a tombstone now plays a prominent role. In contrast, the Aboriginal peoples of Normanton, to the south, lost many of their traditions not only through active suppression by whites, but also by being decimated by disease and massacres and then being shifted about to work on tribally mixed cattle stations and finally to reside in a white dominated town far from most of their traditional territories. ${ }^{22}$ They have been left with a cattle camp culture that is both less traditional and less westemised than that of the people of Kowanyama.

\section{3. 'Chellikee Hospital' and the commemoration of historical events}

Many of the island dance songs tell of the composers' perceptions of particular historical events. Some of these events may seem minor to European eyes, such as the day a taipan was seen in the town, or the night the composer was flown into Cairns by air ambulance and was impressed by the multitude of lights. Other songs were more clearly composed to commemorate particular events of great import to the community as a whole.

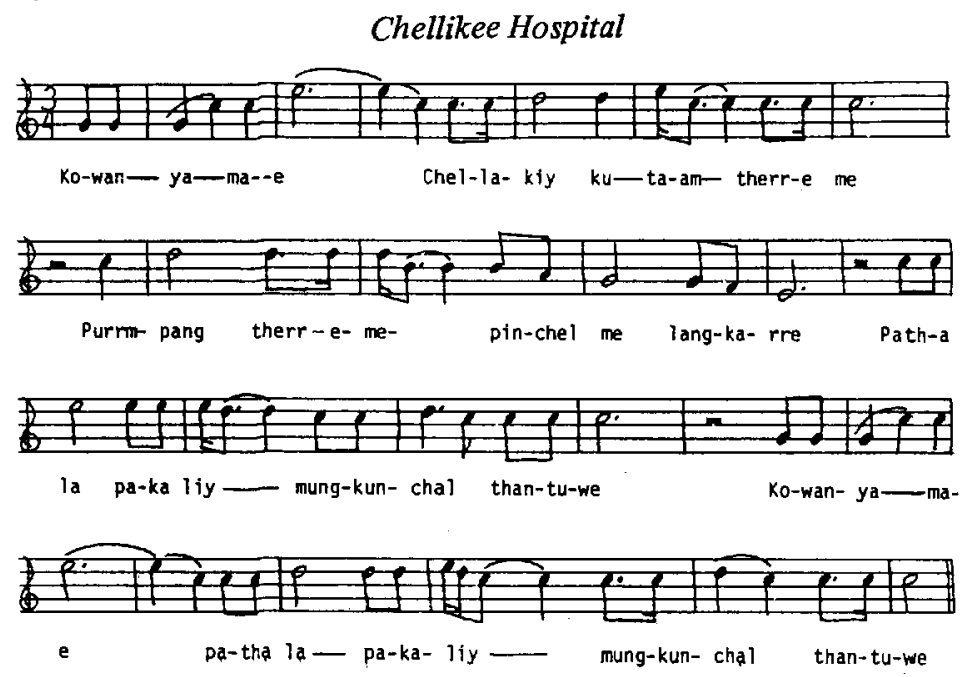

22 See Black 1976. 


\section{KOKO-BERA MUSIC}

(lyrics as sung, with ' added to show the beginnings of musical bars:

Kowanyama' e... ,

Chelakiy ku'am therreme- -

Purrmpang therremen pinchelme- - langkarre- - .

Patha la paka liy mungkunchal thantuwe-..-)

Kowanyama, . chéləkey kutám thərré-m.

doctor new is standing

Purrpáng therromén pinchél-m.

light(s) in a row are burning

Path la pa'ko-(1) liy mungkunchá-1 thántow.

place this found yonder became extinct they

In Kowanyama a new Chélakay is standing;

Lights are burning here in a row;

Those who found this place are dead and gone.

'Chellikee Hospital' was composed on the occasion of the opening of a new clinic in about 1976. The clinic was named Chellikee after the Koko-Bera word ( $p a)$ chélakay '(traditional or modern) doctor'; the first line of the song can thus use this word to speak of 'a new doctor' as well as the name of the clinic. The second line gives the composers' impression of one aspect of the hospital: it seems to refer to the row of lights from the in-patient rooms along the corridor. The last refers to the early missionaries in general, but especially to the Reverend Chapman, to whose memory the clinic was dedicated.

\section{4. 'Magnificent Hotel' and the poetry of the dance}

Like the preceding song, 'Magnificent Hotel' commemorates a specific public event, namely the 1977 opening of a beer canteen named after the Magnificent River, along which Kowanyama was built. It is especially poetic in its lyrics, and it is one of the songs for which the accompanying choreography can be reported here.
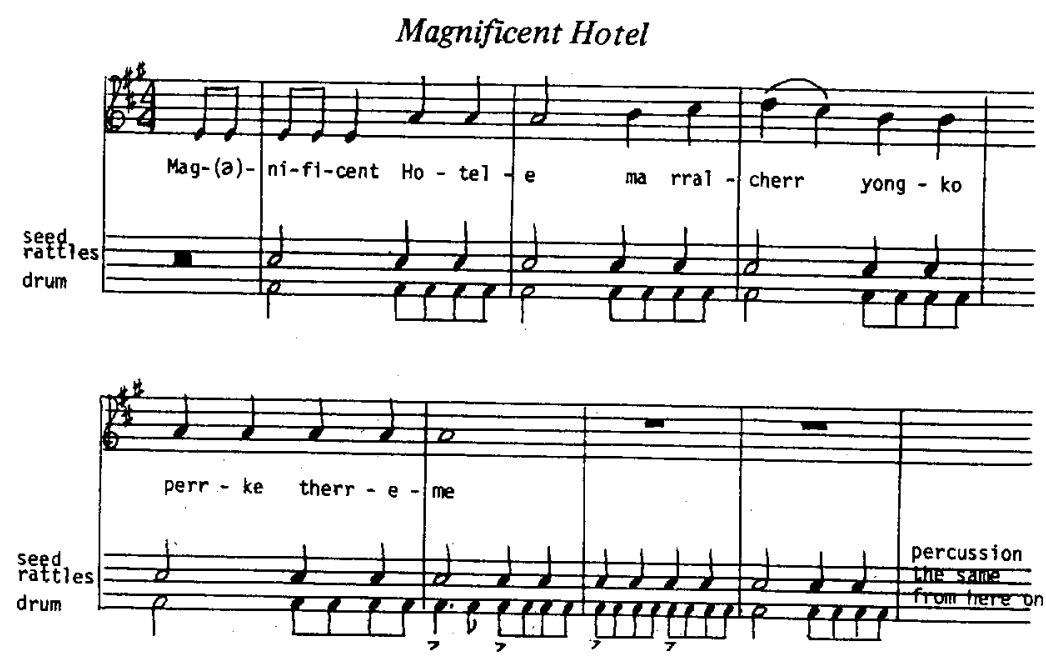


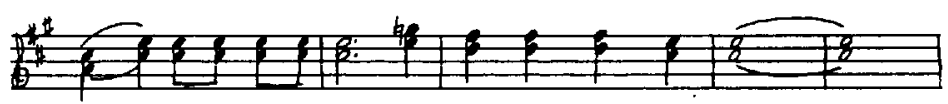

Mim -.- purr-a -purr-o wak ka - nin - yin therr - e - me -
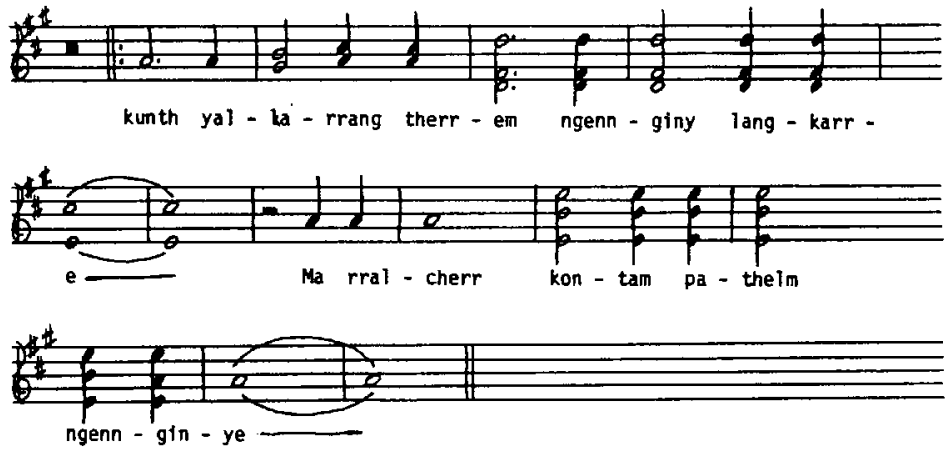

(Lyrics as sung, with' marking beginnings of musical bars:

'magánificen' Hotel' e ma rralcherr yongko 'perrke therreme- -

'Mim purropurre' wa kaninyin therreme-..

'Kunth yalkarrang theirem ngennginy langkairre- -

Ma rralcherr kontam pathelm ngennginye- -)

Magnificent Hotel, ma(y) rralchérr yəngkó perrk thərré-m.

food honey with open stands

Mim púrrpurr wa(k) kanínyant therré-m.

animal feather heap above stands

Kunth yəlkárreng thərré-m ngénngəny lángkərr.

line(s) long stand we (inclusive) here

$\mathrm{Ma}(\mathrm{y})$ rrolchérr kónt-əm(p) pothél-m ngénngəny.

food honey from baler shell drink we (inclusive)

Magnificent Hotel, standing open with honey,

Standing on the heaps of feathers;

We stand here in long lines,

We drink honey out of baler shells.

The song begins by picturing the canteen as standing open with 'honey', i.e. beer, because of its colour (like that of introduced honey, at least) and desirability. The 'mounds of feathers' in the second line relate to the fact that the canteen was built on an earlier kapmari (or cupmaori) ground - northern Queenslanders, at least, know the local English word kapmari, perhaps originally from a language of Papua New Guinea, to refer to the 'earth ovens' in which such animals as plain turkey and wallaby are cooked luau-fashion. At this point the dancers make an inverted ' $V$ ' with their hands over their heads, to represent the mounds. The third line refers to the fact that people form two queues in front of the canteen, one for men and one for women, as they wait for their thrice-weekly ration of five or six tins of beer. 


\section{KOKO-BERA MUSIC}

At this point the dancers, who were in a square formation, themselves form two lines, and look from side to side as they march in place. This continues during the last line, but with the dancers raising their hands to their mouths as they 'drink honey from baler shells'. In traditional times a mixture of sugarbag honey and water was in fact drunk from baler shells, but only indirectly by dipping it out with pieces of pukán ngamékath 'sugarbag grass' (i.e. Alloteropsis semialata).

\section{5. 'Groote Eylandt' and innovations in the style}

From the musicological analysis in the following section you will see that island dance songs tend to follow a closely defined pattern; it would not be hard to program a computer to chum out typical island style melodies. Whereas the creative genius of composers is thus more often seen in such other aspects of the dances as their lyrics and choreography, it can sometimes be seen in the way composers have been able to deviate from the norms of the style and yet produce compositions that clearly fall within the genre. One strikingly beautiful example, recorded by Peter Sutton at Lockhart, was an island dance performed simultaneously with a traditional song in strange counterpoint. 'Groote Eylandt' is perhaps less striking in its deviation, but it does serve as an example of a song that is atypical in its failure to rise a perfect fourth from its beginning, and which, like 'Chellikee Hospital', is not in march time.

\section{Groote Eylandt}

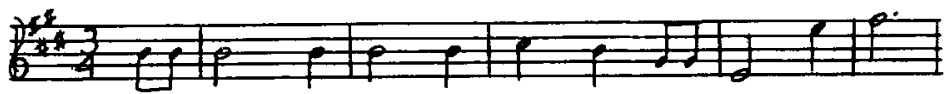

D. C. - 3 yong - ko ngan - then - tuw ka-le- me $11-$

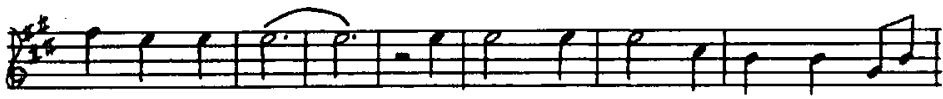

-y wal - pl-ye—yung - kal po-korr ka - nin - yint ka-le-
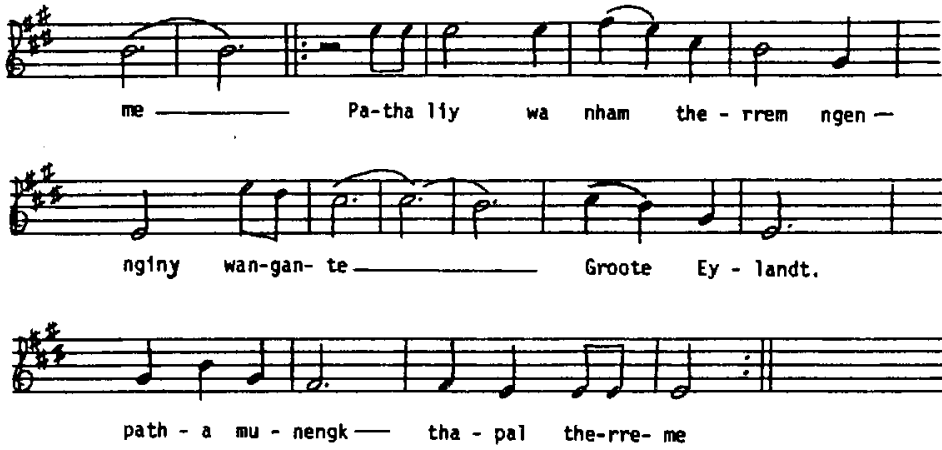
(Lyrics as sung, with ' marking beginnings of musical bars:

$D C-3$ yongḱ, nganthentuw kaléme 'ii- -'-y walpiye-...

Yungkal pokorr kaninyint kaleme- -

Patha 'liy wa' nham therrem ngennginy wangante- - - -

'Groote Eylandt 'patha munengk 'thapal therreme--)

$D C \cdot 3$ yəngkó ngənthéntəw kəlé-m liy wálpay.

with we (exclusive) are going there west

Yungkál pakórr kanínyant kalé-m.

sea middle above are going

Path liy wa(y) nha-m tharré-m ingénngeny, wángant,

place that (question) see(s) are standing we (inclusive) from the west

Groote Eylandt, path mun-éngk thápəl thərré-m.

place on an island big are standing

With the DC3 we're going

There to the west,

Going above the middle of the sea.

Look at that place where we were standing,

Off in the west,

On Groote Eylandt,

Standing on a big island.

Isaac Zingle composed 'Groote Eylandt' after returning from a dance festival in northeastern Amhem Land. The melody is sweeping and majestic, capturing the spaciousness of the Gulf of Carpentaria as seen from a DC3 aircraft evenly throbbing away in a slow $3 / 4$ time. The choreography captures the mood by portraying people rowing boats and then pausing to point up at the DC3 crossing the sky. The main point of the lyrics is that when the travellers first saw Groote Eylandt from the air it looked tiny, but after they landed they looked around and saw that it was quite a big place indeed.

\section{MUSICAL ANALYSIS}

All five songs have four phrases each. Three of the five songs repeat a phrase, either the first or the last, to give a form of $\mathrm{ABCC}$ or $\mathrm{ABCA}$. The other two songs have four different phrases. A number of island style songs rise or fall by the interval of an octave somewhere in the melody, and this is clearly seen in measure 3 of the song, 'Groote Eylandt'.

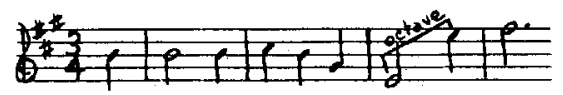

Shapes of phrases vary, but in all but 4 out of 20 phrases in the five songs, the cadence consists of a descent to the tonic following a repetition of the supertonic.
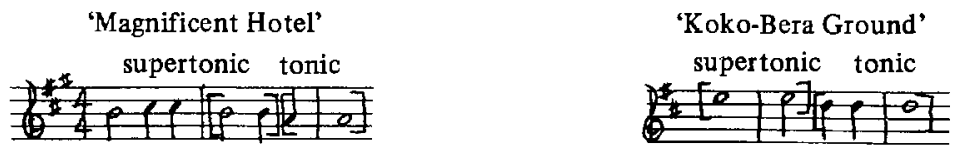


\section{KOKO-BERA MUSIC}

In all but one of the songs, the first intervallic leap is a rising perfect fourth followed by a rising major third. Since all of the songs begin on the dominant, a second inversion tonic chord is formed within the first few notes of the melody, as shown at the start of 'Chellakee Hospital'.

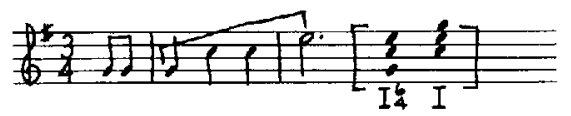

If a triad is outlined in the melody, it is either the dominant or the tonic of the key.

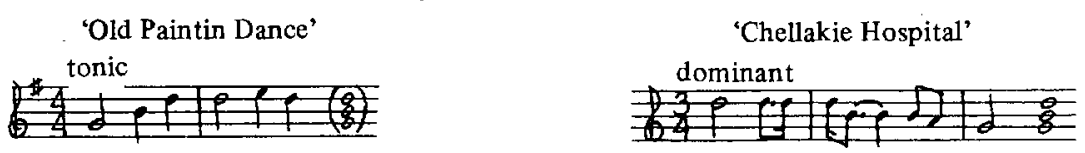

Many island style songs include long syllable strings recited on one note. The 'Old Paintin' Dance' does this in measure 10, where the family name, Pekanpenpew, plus other words, are recited on the submedient (11 syllables). This differs from many other island style songs where the reciting tone is usually on the first or third of a tonic or dominant triad.

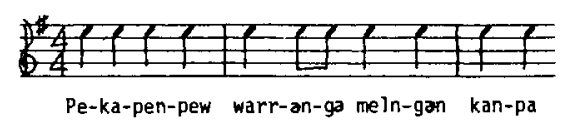

The songs are based on the three primary chords, tonic, dominant, and subdominant, which makes guitar or ukulele accompaniment an easy matter. The vocal harmony found in island style is totally unlike harmonies in traditional musics of Australia. Such harmony may occur above or below the melodic line. LaMont West documents an Aboriginal term for descant, or harmony above, as being 'kordo' which may simply be a variant of the English word, 'chord'.23 In 'Magnificent Hotel' we see harmony both below the melody and above it, especially in the final phrase. Whenever there is a cadence ending on the tonic note, the harmony (whether it is above or below the melody) goes from the dominant to a unison (or octave) tonic.

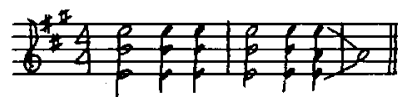

Island style melodies most commonly have a range of an octave to a twelfth with some songs notated as being as narrow as a fourth or as wide as a fourteenth. The five notated songs have a slightly narrower range than the norm, ranging from a sixth to a ninth.

\section{Instrumental accompaniment}

In island dance, the percussion tends to change its pattern at each place in the song where the vocal cadence comes to an end and there is a rest for the voices. We see this pattern in the two songs where the instrumental accompaniment is notated. In both cases, the instrumental part is notated for the beginning of the song only, but the same rhythm continues to the end of the song. In 'Magnificent Hotel' the drum part at the

23 West 1960:12. 


\section{ABORIGINAL HISTORY 1983 7:2}

musical cadence changes to a straight quaver beat after a dotted figure which serves to 'kick off' the new rhythmic intensity. The seed rattle part also changes to a straight crotchet figure at the cadence. In 'Old Paintin' Dance' the drum part changes from a pattern of $\downarrow \downarrow d$ to a straight quaver beat at the cadence. This technique of using a heavily accented quaver pattern at the place of rest for the voices gives an effective, exciting instrumental interlude that increases the emotional tension of the song so that the voices come in on a vibrant pitch.

Island style songs may represent the only oral literature that some Cape York people possess, and the songs form a vital part of twentieth century Cape York culture.

\section{BIBLIOGRAPHY}

Alpher, Barry. 'Phonological peculiarities of Yir-Yoront Song Words', in P. Sutton ed. Languages of Cape York. Canberra, 1976:78-83.

Beckett, Jeremy. 'Mission, Church and Sect in Oceania', in J. Boutilier et al. eds. Association for Social Anthropology in Oceania, Monograph Series, Monograph No. 6. Ann Arbor, 1978: 212-219.

Black, Paul. 'The Kurtjar in Recent Years', AIAS Newsletter, n.s. 9, 1976:54-57.

Chase, Athol. Which way now? Tradition, continuity and change in a north Queensland Aboriginal community. $\mathrm{PhD}$ thesis, University of Queensland, 1980.

Haddon, A.C. ed. Reports of the Cambridge Anthropological Expedition to Torres Straits, vol. 3, Miriam-English Vocabulary. Cambridge, 1907.

Laade, Wolfgang. Catalogue of field tape recordings, vol. 1, Cape York Peninsula. 1963-64.

Catalogue of field tape recordings, vol. 3, Torres Strait Islands: Eastern Islands. 1963-65.

Moyle, Alice. 'Aboriginal Music on Cape York', Musicology III (Journal of the Musicological Society of Australia), 1968-69:4-12.

- Companion booklet for AIAS LP disc, AIAS/12, Songs from North Queensland. Canberra 1978.

Sommer, Bruce and James Marsh. 'Vernacular and English: language comprehension by some North Queensland Aborigines', Anthropological Linguistics, 11, 1969:48-57.

West, LaMont. Dubbings and miscellaneous notes on the LaMont West tapes and films held by the AIAS and others, 1960. 